\title{
Organosolv lignin aggregation behaviour of soluble lignin extract from Miscanthus $x$ giganteus at different ethanol concentrations and its influence on the lignin esterification
}

\author{
Muhammad Hazwan Hamzah ${ }^{1,2,3^{*}}$ (D) Steve Bowra ${ }^{4}$ and Philip Cox ${ }^{5}$
}

\begin{abstract}
Background: Lignin is the second most abundant naturally occurring biopolymer from lignocellulosic biomass. While there are several lignin applications, attempts to add value to lignin are hampered by its inherent complex and heterogenous chemical structure. This work assesses the organosolv lignin aggregates behaviour of soluble lignin extract derived from Miscanthus $\times$ giganteus using different ethanol concentrations (50\%, 40\%, 30\%, 20\%, 10\% and $1 \%)$. The effect of two different lignin concentrations using similar ethanol concentration on the efficacy of esterification was studied.

Results: Overall, particle size of lignin analysis showed that the particle size of lignin aggregates decreased with lower ethanol concentrations. 50\% ethanol concentration of soluble lignin extract showed the highest particle size of lignin $(3001.8 \mathrm{~nm}$ ), while $331.7 \mathrm{~nm}$ of lignin particle size was recorded at 1\% ethanol concentration. Such findings of particle size correlated well with the morphology of the lignin macromolecules. The lignin aggregates appeared to be disaggregated from population of large aggregates to sub-population of small aggregates when the ethanol concentration was reduced. Light microscopy images analysis by ImageJ shows that the average diameter and circularity of the corresponding lignin macromolecules differs according to different ethanol concentrations. The dispersion of lignin aggregates at low ethanol concentration resulted in high availability of hydroxyl group in the soluble lignin extract. The efficacy of the lignin modification via esterification was evidenced directly via FTIR using the similar ethanol concentration of soluble lignin extract at different lignin concentrations.
\end{abstract}

Conclusion: This study provided the understanding of detail analysis on particle size determination, microscopic properties and structural insights of lignin aggregates at wider ethanol concentrations. The esterified lignin derived at $5 \mathrm{mg} / \mathrm{mL}$ is suggested to expand greater lignin functionality in the preparation of lignin bio-based materials.

Keywords: Lignocellulosic, Lignin, Aggregates, Concentration, Esterification

\footnotetext{
*Correspondence: hazwanhamzah@upm.edu.my

1 Department of Biological and Agricultural Engineering, Faculty of Engineering, Universiti Putra Malaysia, 43400 Serdang, Selangor, Malaysia

Full list of author information is available at the end of the article
}

(c) The Author(s) 2021. Open Access This article is licensed under a Creative Commons Attribution 4.0 International License, which permits use, sharing, adaptation, distribution and reproduction in any medium or format, as long as you give appropriate credit to the original author(s) and the source, provide a link to the Creative Commons licence, and indicate if changes were made. The images or other third party material in this article are included in the article's Creative Commons licence, unless indicated otherwise in a credit line to the material. If material is not included in the article's Creative Commons licence and your intended use is not permitted by statutory regulation or exceeds the permitted use, you will need to obtain permission directly from the copyright holder. To view a copy of this licence, visit http://creativecommons.org/licenses/by/4.0/. The Creative Commons Public Domain Dedication waiver (http://creativeco mmons.org/publicdomain/zero/1.0/) applies to the data made available in this article, unless otherwise stated in a credit line to the data. 


\section{Background}

An integrated biorefinery is the sustainable processing of biomass into a spectrum of bio-based products such as food, feed, chemical and materials as well as bioenergy including power, heat and biofuels [1]. Within the integrated biorefinery concept, an area of research that has gained significant interest is the processing of lignin which, as said, is the second most abundant natural polymer after cellulose and hemicellulose [2,3]. Once lignin is recovered, the major goal has been to develop addition added value applications. However, the processing of lignin is not without its problems. Despite the fact that it is difficult to use lignin directly in various bio-based material applications such as cosmetics, pharmaceuticals and polymer composites due to the recovery of lignin from the product stream, purification of lignin, the heterogenous structure of lignin and the reactivity of lignin [4-6]. This complexity means that development of isolation techniques and chemical modification to produce a selective product is difficult.

Nevertheless, lignin could offer a substantial opportunity in enhancing the operation of a lignocellulosic biorefinery for high-value application using various technologies. The use of unmodified lignin in polymer materials also is limited in the field of adsorbing and carbon materials [7]. Numerous studies have investigated the incorporation of lignin into a polymeric matrix such as packaging film [8], polyurethane [9] and adhesives [10]. The bio-replacement ratios in lignin utilisation for biomaterials are very low in the range of 5 to 30\% [11]. Further increasing the bio-replacement ratios resulted in substandard of physico-chemical properties of lignin biomaterials. Currently, efforts to increase the use of lignin in biopolymer applications is related to the degradation or deconstruction of lignin to small monomers by depolymerisation and chemical modification of lignin to increase reactive sites into lignin molecules $[12,13]$. Moreover, the available reactive hydroxyl groups in lignin demonstrate possibilities for chemical modifications such as esterification prior to lignin valorisation into valuable materials. The incorporation of modified lignin into polyesters, polymeric material is recommended to break up the lignin complexes structure, increase the plasticising ability, therefore the blends of modified lignin with polymer possess good physico-chemical properties.

Lignin exists as a globular supramacromolecular structure which has many interactions such as lignin-lignin and lignin-polysaccharide interactions, and highly reactive, that tend to form large aggregates, thereby affect the biomass deconstruction [14]. In lignin synthesis, the formation of lignin globule began with modules that consist of various monomers. Then, the polymerisation of monomers formed supermodules and globules that made up a large number of supermodules [15]. In lignin aggregation, Norgren et al. suggested that the modes of aggregation starting from macromolecular lignin and the final product of fractal lignin clusters that has non-integer dimensionality of complex structures [16]. The modes of aggregation presented as dissolved macromolecules and few steps occurred during aggregation including lignin self-associates and colloidal lignin particles.

Lignin isolated via different process configuration can vary widely in physico-chemical properties. The solvent concentration had influence on the lignin purity and recovery as well as the other physical, chemical and structural properties of lignin $[6,17]$. In the context of growing interest in developing value-added applications for lignin, the relationship between solvent concentration and the resultant lignin macromolecules' is complex. Associations of the lignin molecule under different conditions vary: the rearrangement of the hydrogen bonds of hydroxyl group play major role and the availability of the hydroxyl group in soluble lignin extract could influence the physico-chemical properties of lignin aggregates in modifying and converting lignin into useful renewable materials. Lignin has a number of functional groups that can generate intermolecular and intramolecular hydrogen bonds, affecting its compatibility with other host matrices in bio-based formulation [18].

Therefore, the study explored the lignin aggregates deconstruction at different ethanol concentration of soluble lignin extract by dilution. The investigation presented in this study is imperative and could facilitate improved understanding of structural complexity of soluble lignin extract behaviour obtained prior to lignin valorisation into valuable materials. Characterisation of the resulting soluble lignin extract was carried out by particle size analysis, light microscopy, imageJ and phenolic hydroxyl group analysis. Subsequently, the effect of two different solute or lignin concentrations using similar ethanol concentration on the efficacy by esterification was examined. This work is very important since there are no studies available in the literature concerning the use of soluble lignin extract directly after delignification or without recovering the lignin for lignin modification process. The latter was obtained by exploring the changes in chemical structure of modified lignin after esterification under different lignin concentrations, the variation in the chemical properties of lignin macromolecule was tentatively related to the replacement of hydroxyl groups by ester substituent [19]. This reduces the number of hydrogen bonds and causes an increase in the free volume in the molecule, imparting mobility of the chains on the ester group [20]. Information on the chemical characteristics of modified lignin should shed light on enhancing its potential uses in value-added polymeric materials. 


\section{Methods}

Materials

The lignocellulosic biomass used was air-dried Miscanthus $x$ giganteus $(M x G)$ provided by the Institute of Biological, Environmental and Rural Sciences (IBERS, UK) in collaboration with Phytatec (UK) Ltd. The biomass was harvested in Aberystwyth, Wales, United Kingdom, and kept in a cool, dry and dark place throughout the study.

\section{Biomass preparation}

The steps taken for biomass preparation were performed using the methods developed within research group [21]. Prior to hydrolysis, the $M x G$ was mixed in distilled water then warmed to $50{ }^{\circ} \mathrm{C}$ to soften the grass. The mixture was then soaked for $20 \mathrm{~min}$ to rehydrate the grass. The mixture was milled for $3 \mathrm{~min}$ in a domestic blender to reduce the particle size of the material. The grinding conditions of the temperature, soaking time, grinding time, and the solid-to-liquid ratio were previously optimised to yield an average particle size of $500 \mu \mathrm{m}$ [22].

The $M x G$ slurry was placed inside the reactor directly after the sample preparation at $120{ }^{\circ} \mathrm{C}$. The sequentially processed $M x G$ obtained at $120^{\circ} \mathrm{C}$ was used for biomass hydrolysis at $180{ }^{\circ} \mathrm{C}$ and $200{ }^{\circ} \mathrm{C}$. The sequentially processed $M x G$ was mixed in water and a 1:1 ethanol-water solution for $180{ }^{\circ} \mathrm{C}$ and $200{ }^{\circ} \mathrm{C}$, respectively, by warming to $50{ }^{\circ} \mathrm{C}$ and a wetting time $5 \mathrm{~min}$ prior to each hydrolysis step. Absolute ethanol (Fisher Scientific, UK) was used as reagents.

\section{Biomass hydrolysis}

The steps taken in extracting lignin in this work are outlined in Fig. 1. The $M x G$ slurry was transferred to a 500$\mathrm{mL}$ stirred pressure vessel (Alloy C276, Parr, IL, USA). The reactor was closed and pressurised with the desired gas to $5 \mathrm{MPa}$. The set point temperature was increased to the set temperature and was kept stable during the reaction time by a controller (4386, Parr). After the reaction, the reactor temperature was decreased through a cooling system with a cooling coil inside the pressure vessel in which a coolant flew at an initial $-7{ }^{\circ} \mathrm{C}$. When the temperature fell below $50{ }^{\circ} \mathrm{C}$, the reactor was depressurised slowly to atmospheric pressure before the reactor was opened. Finally, the solution and solid fibres were separated using a laboratory test sieve (BS410-1 size $45 \mu \mathrm{m}$, Endecotts Ltd, England) for biomass hydrolysis at $120^{\circ} \mathrm{C}$ and $180{ }^{\circ} \mathrm{C}$. The solid fibres were placed in the drying cabinet $\left(65^{\circ} \mathrm{C}\right)$ until it reached constant weight for later use within research group. The liquid fraction or filtrate for biomass hydrolysis at $200{ }^{\circ} \mathrm{C}$ was recovered by vacuum filtration through a Pyrex sintered disc porosity 2, rinsed with mixture of distilled water:ethanol (1:1).
The $M x G$ was treated through a three-stage temperature profile sequential batch extraction method adapted from Hamzah et al. [23] to differentially separate extractives, hemicellulose, cellulose, and lignin. The first step applied subcritical water at $120{ }^{\circ} \mathrm{C}$ with an equilibrium time of $30 \mathrm{~min}$ and $5 \mathrm{MPa}$ of nitrogen gas (compressed oxygen-free nitrogen, $\mathrm{BOC}, \mathrm{UK}$ ) to remove water-soluble extractives that could have interfered with the isolation and later analytical steps. The second step used a subcritical water at a regime of $180{ }^{\circ} \mathrm{C}$ and a reaction time of 30 min under $5 \mathrm{MPa}$ of nitrogen gas to hydrolyse hemicelluloses prior to delignification. The final step involved lignin extraction via a subcritical water with associated modifiers using a 1:1 ethanol-water mixture at $200{ }^{\circ} \mathrm{C}$, a reaction time of $60 \mathrm{~min}$, and $5 \mathrm{MPa}$ of carbon dioxide gas (vapour withdrawal, BOC, UK).

\section{Particle size analysis}

Soluble lignin extract or known as filtrate from biomass hydrolysis at $200{ }^{\circ} \mathrm{C}$ containing $50 \%$ (by volume) of ethanol from the delignification process was used as starting material and diluted with water to different ethanol concentrations as shown in Fig. 2. The samples were ultrasound-treated for $10 \mathrm{~s}$ at room temperature using $500 \mathrm{~W}$ Fisher Scientific ${ }^{\mathrm{TM}}$ Model 505 Sonic Dismembrator prior to measurement. The measurement of the diameters was carried out in triplicate and the results were reported as averages of reading.

\section{Malvern Zetasizer Nano ZS}

Lignin particle size was performed according to the protocol described with modification [24, 25]. Lignin particle size was analysed at $23{ }^{\circ} \mathrm{C}$. The obtained size distribution represented the dependencies of the relative intensity of scattered light on the hydrodynamic diameter of lignin

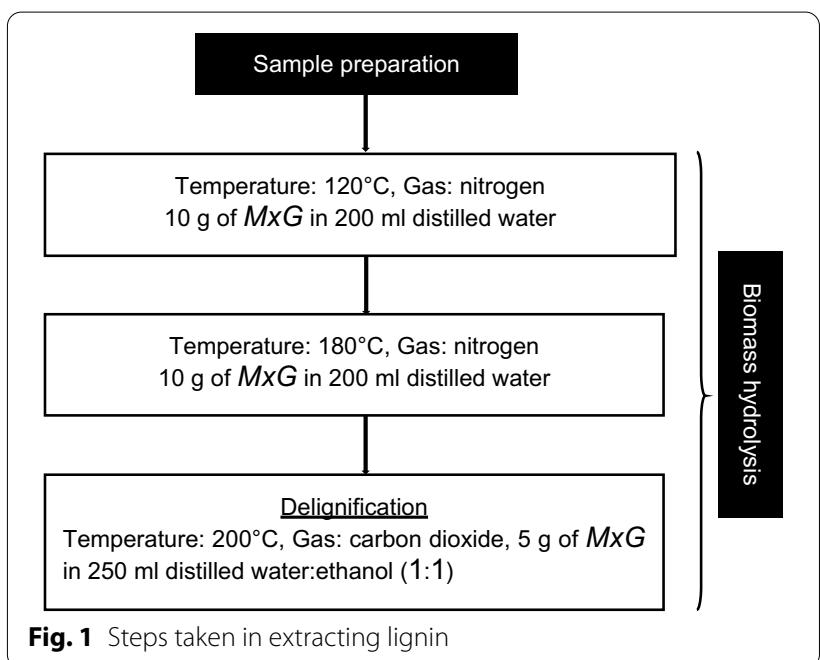


particles. The intensity shows the contribution of a particle size mode to the intensity of scattered light.

\section{Malvern Mastersizer 2000}

A refractive index of 1.6 [26] and absorption of 0.01 for lignin were used by the instrument to calculate the particle size distribution [27]. Lignin particle size was analysed at $23{ }^{\circ} \mathrm{C}$. The mean particle size was reported in terms of D3,2 values. The D3,2 is the surface area mean diameter and refers to the diameter of a sphere equivalent volume to surface area of the particles in the sample.

\section{Light microscopy (LM) analysis}

$0.01 \mathrm{~mL}$ of soluble lignin extract at different ethanol concentrations were examined under the LM (Olympus BX50, Japan) at $100 \times$ magnification equipped with a digital camera (Motic MC35X, China).

\section{Image J analysis}

Using images captured by the light microscope, particle size analysis was conducted by ImageJ freeware (1.50v). Prior to particle size analysis, 10 recorded images were calibrated, despeckled to reduce noise and converted to grayscale. Image analysis captured a 2-dimensional image of a 3-dimensional particle and the projected area of lignin macromolecules (Eq. 1) enclosed by the outer contour of a particle from 2-dimensional image was analysed based on assumption that centre of mass (similar to centroid but brightness weighted) $[28,29]$ :

$$
A=\pi r^{2}
$$

where $A$ is projected area, $\mu \mathrm{m}^{2}$ and $r$ is the radius of circle.

The circle equivalent diameter which is the diameter of a circle with the same area as the 2-dimensional images of the particle was calculated using Eq. 2 [28]:

$$
D_{\mathrm{CE}}=\sqrt{\frac{4 A}{\pi}},
$$

where $D_{\mathrm{CE}}$ is circle equivalent diameter and $A$ is projected area, $\mu \mathrm{m}^{2}$.
The circularity, a dimensional value was determined based on the projected area and perimeter of the particle (Eq. 3). The circularity value is indicative of the importance of particle shape in the overall particle behaviour and interaction in terms of particle form and roughness, and therefore the reactivity of lignin macromolecules [30]. Lower circularity $(C \leq 1)$ indicates that the lignin macromolecules are away from a perfectly round and smooth circle [28]:

$$
C=\sqrt{\frac{4 \pi A}{P^{2}}},
$$

where $C$ is circularity, $A$ is projected area, $\mu \mathrm{m}^{2}$ and $P$ is perimeter, $\mu \mathrm{m}$.

\section{Phenolic hydroxyl group determination by ultraviolet- visible (UV-Vis) spectroscopy}

Phenolic hydroxyl group determination via UV-Vis was adapted according to protocol described with modification [31, 32]. $2 \mathrm{~mL}$ of soluble lignin extract at different ethanol concentrations is poured into two 50-mL measuring flasks, one flask is filled to the mark with buffer solution at $\mathrm{pH} 6$ (neutral media, buffer substance: potassium di-hydrogen orthophosphate and disodium hydrogen orthophosphate, Reagecon), and the second with $0.2 \mathrm{~N} \mathrm{NaOH}$ (alkaline media, $\mathrm{pH} 14$, Merck). After stirring, the solutions were poured into 1-cm quartz cuvettes.

UV-Vis absorbance was recorded via a Cary ${ }^{\circledR} 50$ UV-Vis Spectrophotometers (Varian, Inc., USA) in the absorption region $200-450 \mathrm{~nm}$, scan rate $600 \mathrm{~nm} / \mathrm{min}$, data interval $1 \mathrm{~nm}$ and average time $0.1 \mathrm{~s}$. The absorbance difference of the alkaline solution (ionised) with respect to the neutral solution (non-ionised) at $300 \mathrm{~nm}$ and $360 \mathrm{~nm}$ was measured. All experiments were done in triplicate. The average reading was calculated for determination of phenolic hydroxyl groups.

The concentration of total phenolic hydroxyl groups in $\mathrm{mmol} / \mathrm{g}$ was calculated from Eqs. 4 and 5 [32, 33] and applied in this work:

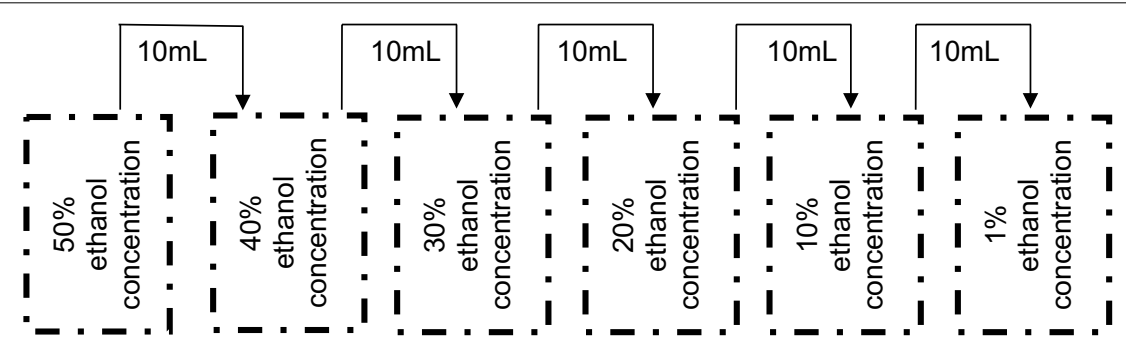

Fig. 2 Scheme of dilution for soluble lignin extract 


$$
\left[\mathrm{OH}_{\text {total }}\right]=0.250 \Delta a_{300 \mathrm{~nm}}+0.107 \Delta a_{360 \mathrm{~nm}} .
$$

Values of $\Delta a(\mathrm{~L} / \mathrm{g} / \mathrm{cm})$ were calculated according to:

$$
\Delta a=D / C l,
$$

where $D$ is optical density/absorption, $C$ is lignin concentration in solution, $\mathrm{mg} / \mathrm{mL}$ and $l$ is cuvette width, $1 \mathrm{~cm}$.

\section{Synthesis of lignin fatty acid derivatives at different lignin concentrations \\ Preparation of soluble lignin extract at different lignin concentrations}

Soluble lignin extract containing 50\% (by volume) of ethanol from the delignification process was used as starting material and diluted to different lignin concentrations as shown in Fig. 3. Two different lignin concentrations were chosen as the sample comparison for this study. The lignin concentration in the starting material was calculated following the determination of total solids in biomass for liquid process samples [34], which gave $5 \mathrm{mg} /$ $\mathrm{mL}$. The lignin concentration is expressed as mass solute in $\mathrm{mg}$ per volume solution in $\mathrm{mL}$. The preparation of second lignin concentration for diluted sample, $1 \mathrm{mg} / \mathrm{mL}$ using the similar ethanol concentration (50\%) by volume was obtained using Eq. 6:

$$
V_{2}=\frac{\left(M_{1} \times V_{1}\right)}{M_{2}},
$$

where $M_{1}$ is the lignin concentration of soluble lignin extract at $50 \%$ ethanol concentration $(5 \mathrm{mg} / \mathrm{mL}) ; V_{1}$ is the volume of soluble lignin extract at $50 \%$ ethanol concentration $(15 \mathrm{~mL}) ; M_{2}$ is the lignin concentration of soluble lignin extract $(1 \mathrm{mg} / \mathrm{mL}) ; \mathrm{V}_{2}$ is the volume of soluble lignin extract at $50 \%$ ethanol concentration for $1 \mathrm{mg} / \mathrm{mL}$, $Y \mathrm{~mL}$; and the amount of ethanol-water mixture (1:1) need to be added to the soluble lignin extract, $X \mathrm{~mL}$.

\section{Lignin esterification}

Lignin-fatty acid derivatives were synthesised using a method described by [35] with modification [33], which the soluble lignin extract was used directly for analysis. Lignin esterification was performed for 5 and $1 \mathrm{mg} /$ $\mathrm{mL}$ of soluble lignin extract to enable comparison of the chemical properties of esterified lignin at both these concentrations. $15 \mathrm{~mL}$ of soluble lignin extract was placed into a $250-\mathrm{mL}$ beaker and stirred with a magnetic stirrer. Pyridine ( $2.75 \mathrm{~mL}$ ) (Sigma-Aldrich, United Kingdom) was used as catalyst and dodecanoyl chloride $(0.9 \mathrm{~mL})$ (Sigma-Aldrich, United Kingdom) was added into the soluble lignin extract. The reaction was carried out at $20{ }^{\circ} \mathrm{C}$ for $2 \mathrm{~h}$, after which the solution was decanted directly into $650 \mathrm{~mL}$ of $2 \%$ ice-cold hydrochloric acid
(VWR, United Kingdom) and stirred for 5 min, resulting formation of a brownish ester layer at the top of a yellowish solution, mainly consisting of the excess acid, alcohol and water which separated under the ester layer. The ester layer was separated via a Buchner funnel with filter paper (Fisher Scientific, Qualitative, $150 \mathrm{~mm}$ ), and washed with excess distilled water and ethanol (1:1) to remove unreacted fatty acids. Then, the esterified lignin was further directly analysed for its chemical structure characterisation via Fourier transform infra-red (FTIR).

\section{FTIR analysis}

FTIR analysis was performed without any pre-treatment for the samples. The IR spectra measurements were taken via a Nicolet 380 FTIR-Thermo Electron Corporation over a spectral range from 4000 to $600 \mathrm{~cm}^{-1}$ with resolution of $4 \mathrm{~cm}^{-1}$ and accumulation of 32 scans.

\section{Results and discussion}

\section{Particle size analysis by Zetasizer Nano ZS}

Figure 4 shows a gradual decrease in the average particle size of lignin macromolecules as the ethanol concentration is decreased.

Particle size distributions are shown in Fig. 5a, b for ethanol concentrations of $50 \%, 40 \%$ and $30 \%$; and $20 \%$, $10 \%$, and $1 \%$ ethanol concentrations of soluble lignin extract, respectively.

The behaviour is complex: bimodal distributions are obtained at $50 \%$ and $10 \%$ ethanol concentration, polymodal distributions are observed at 40 and 30\% ethanol concentration whereas, 20 and $1 \%$ ethanol concentration have a unimodal distribution, respectively. To elucidate the features of the particles in more detail, LM was carried out and is described further. At $50 \%$ ethanol concentration of soluble lignin extract, the particle size distribution showed population of large particle size between 712 and $4801 \mathrm{~nm}$. Figure 6a of LM images shows that the population of large particles also was observed. Whilst the overall trend appears to be a reduction of particle size with reducing ethanol concentration, at $40 \%$ ethanol concentration, two different particle populations are observed; a population of small particle between 295 and $495 \mathrm{~nm}$. Figure $6 \mathrm{~b}$ illustrates the evolution of lignin aggregates behaviour (dotted circle-small particles) of $40 \%$ ethanol concentration of soluble lignin extract.

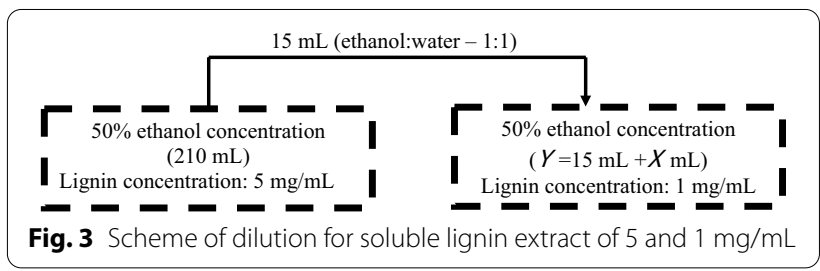


When reducing from 40 to $30 \%$ ethanol concentration of soluble lignin extract, the partitioning behaviour of lignin aggregates can be distinguished, where population of large particles segregated into sub-population of smaller particle (712 and $4145 \mathrm{~nm} ; 342$ and $712 \mathrm{~nm}$ ). However, at $30 \%$ ethanol concentration large aggregates are observed, which is in accordance with the fact that range population of small particle increase from 295 and $495 \mathrm{~nm}$ (40\% ethanol concentration of soluble lignin extract) to, 342 and $712 \mathrm{~nm}$. LM results for the $30 \%$ ethanol concentration are given in Fig. 6c, showing both large and small aggregates.

$20 \%$ ethanol concentration of soluble lignin extract exhibited particle size distribution with a population large particle between 825 and $4801 \mathrm{~nm}$, probably mainly reflecting that the particle population appears surprisingly large and the behaviour of lignin aggregates at $20 \%$ ethanol concentration was inexplicable phenomena. The eccentric behaviour of $20 \%$ ethanol concentration of soluble lignin extract was to found to be in agreement with the optical microscopy imaging analysis depicted in Fig. 6d.

The particle size distribution at $10 \%$ ethanol concentration of soluble lignin extract showed a population of small and large aggregates, with populations between 169 and $6439 \mathrm{~nm}$ (Fig. 6e). Figure 6f shows optical image of $1 \%$ ethanol concentration of soluble lignin extract, where the particles size obtained were between 106 and $1281 \mathrm{~nm}$. The range of particle size for lignin aggregates of $1 \%$ ethanol concentration was apparently smaller in comparison to the lignin aggregates of $10 \%$ ethanol concentration of soluble lignin extract.

\section{Comparison of Zetasizer Nano ZS with Mastersizer 2000} In attempt to capture the significance and comparable findings between the particle size analysis with Zetasizer Nano ZS with other instruments, a series of analysis for

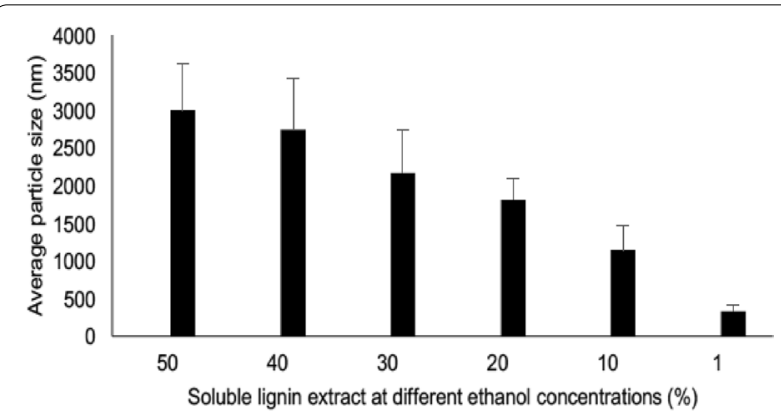

Fig. 4 Particle size at different ethanol concentrations of soluble lignin extract

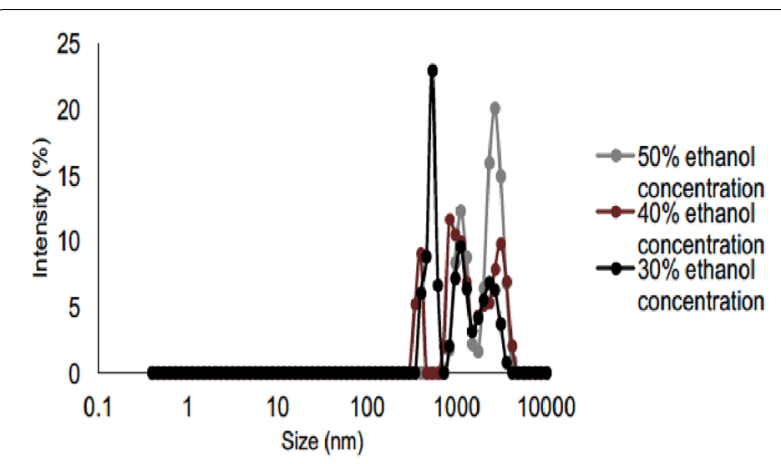

(a)

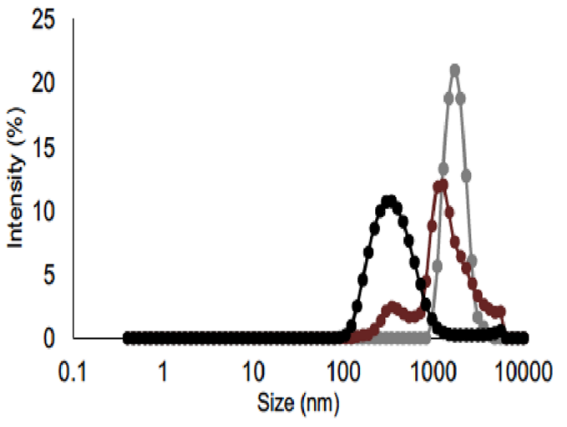

$-20 \%$ ethanol concentration $\rightarrow-10 \%$ ethanol concentration $1 \%$ ethanol concentration

(b)

Fig. 5 Particle size distribution of soluble lignin extract by Zetasizer Nano ZS. a 50, 40 and 30\% ethanol concentration. b 20, 10 and 1\% ethanol concentration

each of soluble lignin extract at different ethanol concentrations was performed via Mastersizer 2000. Detailed information regarding the particle size of soluble lignin extract at different ethanol concentrations is reported in Table 1.

The Sauter mean diameter $\mathrm{D}_{3,2}$ obtained by Mastersizer 2000 shows a downward trend with decreasing ethanol concentration apart from a local increase at 10\% and 20\% ethanol concentration. There is a remarkable drop at $1 \%$ ethanol concentration; the value here approaches the resolution limit of the instrument; thus, it fails to provide an accurate result.

While the surface mean diameter follows a decreasing trend of average particle size from 50 to $30 \%$ ethanol concentration due to breakdown of large particles into population of small particles of lignin aggregates, at $20 \%$ ethanol concentration the value increased up to $6.0 \mu \mathrm{m}$ as the population of large lignin aggregates increased. The other two fractions at $10 \%$ and $1 \%$ ethanol concentration of soluble lignin extract showed a marked drop; it may be speculated that the low ethanol concentration resemble complex formation of lignin aggregates, which affected the measurement of particle size analysis via Mastersizer 2000. 

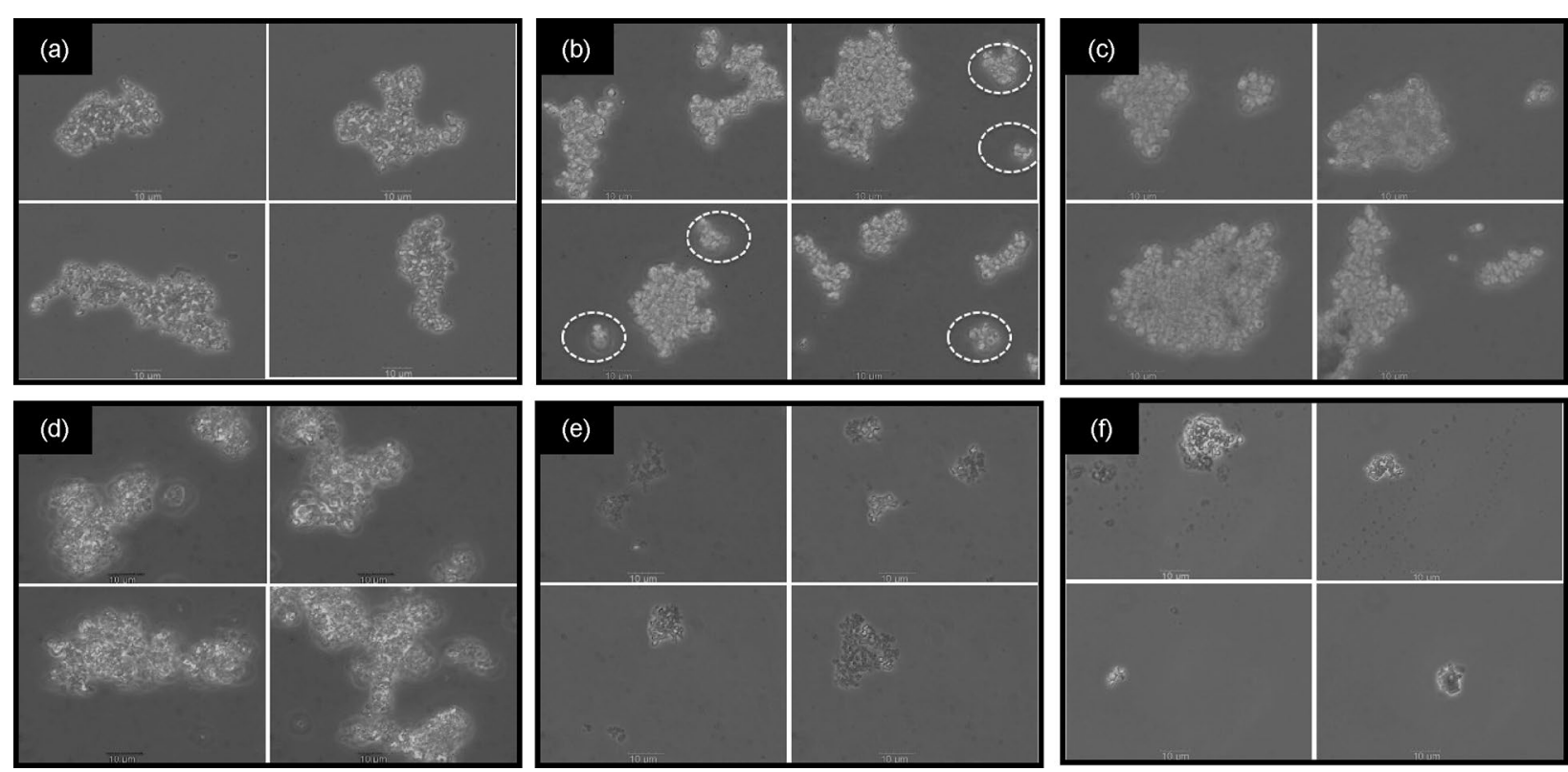

Fig. 6 LM images of a $50 \%$ b $40 \%$ c 30\% d 20\% e 10\% f $1 \%$ ethanol concentration of soluble lignin extract

The $50 \%$ ethanol concentration of soluble lignin extract showed that $D_{\mathrm{v} 10}$ of particles population have the diameter smaller than $3.0 \mu \mathrm{m}$, while $\mathrm{D}_{\mathrm{v} 90}$ of particle population have the diameter smaller than $13.4 \mu \mathrm{m}$. The particles exhibited a tendency to form aggregates which increases with decrease of solute concentration from 50 to $40 \%$ ethanol concentration. The particle size distribution recorded on Mastersizer 2000 for 40\% ethanol concentration of soluble lignin extract indicated that $\mathrm{D}_{\mathrm{v} 10}$ of the sample had diameter smaller than $7.9 \mu \mathrm{m}$ whereas $\mathrm{D}_{\mathrm{v} 90}$ of the sample had diameter smaller than $29.3 \mu \mathrm{m}$.

The data of Mastersizer 2000 in Table 1 indicated that there has a gradual decrease in particle diameter for $\mathrm{D}_{\mathrm{v} 10}$ of the sample from 30 to $1 \%$ ethanol concentration of soluble lignin extract. Nevertheless, $\mathrm{D}_{\mathrm{v} 90}$ of the sample showed a decrease in particle diameter from 30 to $20 \%$ ethanol concentration, slight increase from 20 to $10 \%$ ethanol concentration, and slight decrease from 10 to $1 \%$ ethanol concentration of soluble lignin extract. The variation in the trends in the particle diameter profile might be explained by the aggregation or disaggregation of particles due to the change of particle and their subsequent interaction with the solvent. This includes the motion of solvent relative to the particles that affected the breakage of particle [36].

Theoretically, an increase of ethanol concentration resulted in more dispersion or aggregation of particles in the ethanol-water mixture [38, 39]. As dispersion increases, the particles of molecules decrease [39, 40]. High dispersion of lignin macromolecules also has a broad particle size distribution. Overall, the results in this study also showed discrepancies with the theory. The reason for this rather discrepancies result is still not entirely clear. A possible explanation of contradict lignin aggregates behaviour may be that lignin is an amphiphilic polymer that contains both hydrophobic and hydrophilic segments besides possesses self-assembly behaviour [41]. The hydrophilic segments of lignin macromolecules had an affinity to ethanol, whereas the hydrophobic segments of dissociated lignin aggregate into spherical or rounder shape in the ethanol-water mixture [41-44]. The interaction between amphiphilic properties of lignin and mixture of solvents was very selective and complicated $[45,46]$. A greater focus on lignin solubility parameters and yields of fractionated in ethanol-water mixture is suggested to be conducted in future and these results could produce interesting findings that account more for hydrogen bonding capacity properties.

\section{ImageJ analysis}

In an attempt to evaluate the relationship between different ethanol concentrations with average circle equivalent diameter and circularity of lignin aggregates, analysis of LM images was carried out via the freeware ImageJ. The lignin aggregates behaviour, therefore, needs to be interpreted with caution since the lignin aggregation was very selective according to particular ethanol concentrations. Figure 7 shows the average 
Table 1 Comparison of particle size of soluble lignin extract at different ethanol concentrations

\begin{tabular}{|c|c|c|c|c|c|c|}
\hline \multirow{3}{*}{$\begin{array}{l}\text { Soluble lignin extract at different } \\
\text { ethanol concentrations (\%) }\end{array}$} & \multicolumn{6}{|l|}{ Particle size } \\
\hline & \multicolumn{2}{|c|}{ Particle diameter from Zetasizer Nano ZS (nm) } & \multicolumn{4}{|c|}{ Particle diameter from Mastersizer $2000(\mu \mathrm{m})$} \\
\hline & Particle size distribution & Particle size & ${ }^{\mathrm{a}} \mathrm{D}_{\mathrm{v} 10}$ & ${ }^{\mathrm{b}} \mathrm{D}_{\mathrm{v} 50}$ & ${ }^{c} D_{v 90}$ & ${ }^{d} D_{3,2}$ \\
\hline 50 & $\begin{array}{l}712.4-1718.0 \\
1718.0-4801.0\end{array}$ & 3001.8 & 3.0 & 6.7 & 13.4 & 5.4 \\
\hline 40 & $\begin{array}{l}295.3-458.7 \\
615.1-1484.0 \\
1484.0-4801.0\end{array}$ & 2743.6 & 7.9 & 16.3 & 29.3 & 3.6 \\
\hline 30 & $\begin{array}{l}342.0-712.4 \\
712.4-1484.0 \\
1484.0-4145.0\end{array}$ & 2172.9 & 6.0 & 13.1 & 25.8 & 3.7 \\
\hline 20 & $825.0-4801.0$ & 1815.7 & 3.5 & 7.10 & 13.2 & 6.0 \\
\hline 10 & $\begin{array}{l}164.2-531.2 \\
531.2-6439.0\end{array}$ & 1144.9 & 1.9 & 5.9 & 15.0 & 4.8 \\
\hline 1 & $105.7-1281.0$ & 331.7 & 0.1 & 2.2 & 13.0 & 0.4 \\
\hline \multicolumn{7}{|l|}{$D$ diameter, $v$ volume } \\
\hline \multicolumn{7}{|c|}{${ }^{\mathrm{a}} D_{\mathrm{v} 10}=$ the maximum particle diameter below which $10 \%$ of the sample volume exists } \\
\hline \multicolumn{7}{|c|}{${ }^{\mathrm{b}} D_{\mathrm{v} 50}=$ the maximum particle diameter below which $50 \%$ of the sample volume exists } \\
\hline \multicolumn{7}{|c|}{${ }^{c} D_{v 90}=$ the maximum particle diameter below which $90 \%$ of the sample volume exists } \\
\hline
\end{tabular}

circle equivalent diameter and circularity against ethanol concentrations of soluble lignin extract.

Generally, $11.91 \mu \mathrm{m}$ of average circle equivalent diameter was observed for $50 \%$ ethanol concentration and the average circle equivalent diameter was reduced at $40 \%$ ethanol concentration of soluble lignin extract $(7.43 \mu \mathrm{m})$. However, the reduction of ethanol concentration from 40 to $30 \%$ and $20 \%$ of soluble lignin extract showed a slight rise in the average of circle equivalent diameter of 9.54 and $13.34 \mu \mathrm{m}$, respectively. A decrease in the average circle equivalent diameter was identified towards lowest ethanol concentration from 10 to $1 \%$ of soluble lignin extract, 5.45 and $4.18 \mu \mathrm{m}$, respectively. The explanation for the distinct aggregation phenomena is the selective stability of particulate matter when dissolved within a mixture of solvent environment [47]. The various aggregation driven at different ethanol concentrations may be affected by particle size, shape, flexibility interaction between the particles as well as particles and solvent [48, 49].

Overall, the solvation of solute including solute-solvent and solvent-solvent interactions affects lignin aggregates' behaviour. Furthermore, there was difference in specificities in the interaction of the lignin with two constituent solvents, ethanol and water [46]. The interaction of lignin aggregates was very complicated; either the solute could be demonstrated to be responsible for the aggregates clustering with one component of solvent mixture or solvating in the mixture of solvent aggregates [50]. There are various factors that drive particle aggregation including the type and concentration of solutes in solution as well as other environmental conditions, i.e. temperature, solvent type, $\mathrm{pH}$, and ionic strength [51]. Another important factor that influences the tendency of particle aggregation is the attractive and repulsive colloidal interactions between aggregates such as van der Waals, steric, electrostatic, and hydrophobic forces [51, 52].

The average circularity parameter determines the divergence of a particle from a circle $(C=1)$ due to the change of particle elongation or increase of surface area [30]. Therefore, the average circularity describes the particle morphology of lignin macromolecules at different

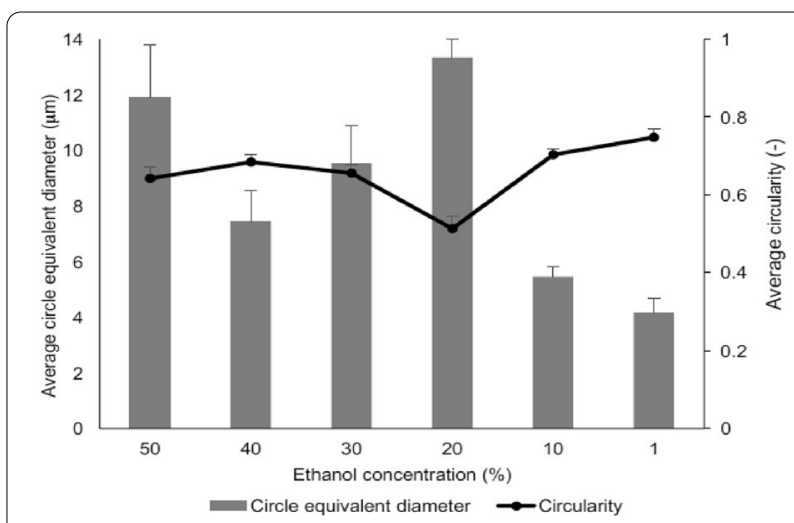

Fig. 7 Average circle equivalent diameter and average circularity at different ethanol concentrations by ImageJ 
ethanol concentration. The low circularity value indicates that the lignin macromolecules are misshapen and irregular lumps rather than defined circular particles. The average circularity increased from 50 to $40 \%$ ethanol concentration of soluble lignin extract (0.65 to 0.68 ), indicating the breaking of large lumps into small pieces. There was a steady decreased in the average circularity from 30 to $20 \%$ ethanol concentration of soluble lignin extract ( 0.66 to 0.51 ) due to the re-aggregation of particle creating more large lumps. An upward trend in the average circularity was observed towards reduction of ethanol concentration from 10 to $1 \%$ ethanol concentration of soluble lignin extract, 0.70 and 0.75 , respectively, which showed that the lignin macromolecules are more small and round.

When comparisons were made between the highest ethanol concentration (50\%) and the lowest ethanol concentration (1\%) of soluble lignin extract, the findings showed that dilution of soluble lignin extract from 50 to $1 \%$ decreased the average circle equivalent diameter and increased the circularity. The diluted soluble lignin extract used by adding more water into the mixture of ethanol and water solution of soluble lignin extract could disrupt the aggregates stability, facilitate and break up the proportion of large lumps of lignin macromolecules to small fragments of aggregates. Hence, the reducing of lignin macromolecules can increase the surface area and more particles are available to react, thus speeding up the reaction rate for chemical processes [53].

Here, it has been suggested that the molecular structure of lignin is highly polar with a large number of hydroxyl $(-\mathrm{OH})$ groups, have tendency for particle aggregation due to the interaction of hydrogen-bonded complexes such as the $\mathrm{O}-\mathrm{H}$ stretching bands, $\mathrm{O}-\mathrm{H}$ bonds of phenols and alcohol as well as $\mathrm{C}=\mathrm{O}$ stretching that would affected the lignin and solvent interaction [45]. Therefore, the study would more convincing if a firm knowledge of the hydrogen bonding properties of hydroxyl group in lignin aggregates and their potential interactions with different ethanol concentrations in addition to structural assembly mechanism could be approached.

\section{Phenolic hydroxyl group determination}

The analysis of lignin functional groups, specifically phenolic hydroxyl groups offers various opportunities for further reactions of the lignin into useful products. The properties of a natural polymer such as lignin make such an analysis difficult due to the complex structure, polyfunctional properties and limited solubility, especially if it has been modified chemically [32]. Nonetheless, there are available methods for phenolic hydroxyl group determination that are de facto accurate for qualitative or quantitative analysis. The determination of phenolic hydroxyl groups may also help to explain the complex particle size and morphology phenomena observed in the previous sections.

To comprehend further estimation of phenolic hydroxyl group present in soluble lignin extract at different ethanol concentrations, the phenolic hydroxyl group contents examined by UV-Vis are presented in Fig. 8.

Figure 8 shows that the total phenolic hydroxyl group increased from 50 to $10 \%$ ethanol concentration of soluble lignin extract. Conversely, the total content of phenolic hydroxyl group decreased at $1 \%$ ethanol concentration of soluble lignin extract. This might be due to the samples analysed do not accurately represent the entire population of lignin in the ethanol-water mixture, which may have affected the accuracy of the method. Overall, the highest result of total phenolic hydroxyl group at $10 \%$ ethanol concentration is similar to those reported by Jääskeläinen et al. [53]. In the ethanol-based fractionation, they reveal that these units were highest at $10 \%$ soluble solvent concentration compared to other lignin fraction. One plausible theory suggests that during the lignin depolymerisation, the $\beta$-ether linkage, the most prevalent inter unit connection in lignin is cleaved, resulted lower molar mass and a new phenolic hydroxyl group is introduced [53, 54]. A similar phenomenon has also been previously reported for different types of green solvent fractionation process $[55,56]$.

A descending trend was observed in which the average particle size obtained by Zetasizer decreased as the ethanol concentration decreased. The results obtained by Mastersizer more related to the aggregation behaviour based on the particle size distribution of Zetasizer. Overall, the results of the total determination of phenolic hydroxyl group delineated the results of particle size analysis by Zetasizer with the exception of $1 \%$ ethanol concentration. The results of quantitative determination of phenolic hydroxyl groups demonstrated a potential indicator of lignin potential reactivity prior modification and further lignin valorisation [54]. These findings suggest that a decrease in ethanol concentration creates more sub-population of aggregates that reduces the average particle size and provides more availability surface area of hydroxyl groups especially phenolic hydroxyl groups as reactive sites for further study of lignin modification via esterification process.

Given that the fact this study was only a preliminary attempt to assess the effect of ethanol concentration on lignin aggregation behaviour, it is hardly surprising that the results showed a complex structural lignin macromolecules dispersion or assembly. It is worthwhile if the validation of availability of phenolic hydroxyl groups in the soluble lignin extract at different ethanol concentrations also could be performed via other methods such as 


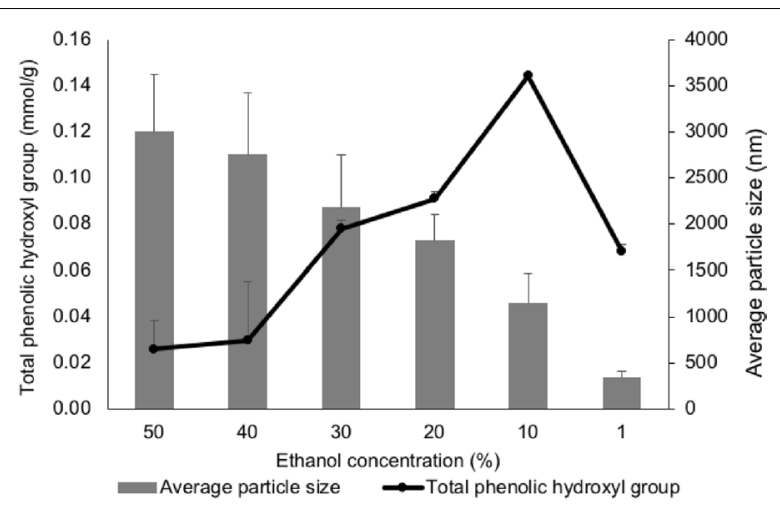

Fig. 8 Total phenolic hydroxyl group and average particle size at different ethanol concentrations

potentiometric titration and nuclear magnetic resonance spectroscopy in future prior to lignin modification via esterification process.

Esterification of lignin was expected to be an easy route to improve the physico-chemical properties of lignin, thus significantly expanding lignin potential for various industrial applications [58]. In lignin modification processes, it might be postulated that the high content of free hydroxyl groups in lignin could be substituted by ester groups, to provide more reactive sites for lignin reactivity. The usual approach to modify lignin via esterification is to dissolve lignin in a powder form into various solutions such as dimethylformamide and dioxane prior to synthesis of esterified lignin. Here, a less costly approach is suggested to use directly soluble lignin extract of water-ethanol mixture ( $50 \%$ by volume of ethanol) after delignification of sequential extraction processing routes for lignin modification process. The lignin concentration of soluble lignin extract after delignification for sequential extraction processing routes was $5 \mathrm{mg} / \mathrm{mL}$. It was recommended that the comparison for the esterification study was conducted between $5 \mathrm{mg} / \mathrm{mL}$ and lower lignin concentration than $5 \mathrm{mg} / \mathrm{mL}$ of soluble lignin extract using similar ethanol-water composition ( $50 \%$ by volume), $1 \mathrm{mg} / \mathrm{mL}$. The comparison of esterification reaction between different lignin concentrations attempted to demonstrate the effect of different availability of hydroxyl groups on chemical properties of esterified lignin.

\section{FTIR analysis}

The FTIR spectra of the resulting solid fraction of modified lignin at 5 and $1 \mathrm{mg} / \mathrm{mL}$ lignin concentration are compared in Fig. 9. Additional samples of liquid fraction via lignin esterification were analysed for comparison study (1) filtrate, (2) dodecanoyl chloride; and (3) blank solution contains ethanol-water mixture $(50 \%$ by volume), pyridine, dodecanoyl chloride and $2 \%$ of icecold hydrochloric acid.

The wavenumbers at 3400, 2938, 2850, 1800, 1760, 1740 , and $1700 \mathrm{~cm}^{-1}$ of FTIR spectra could be used as physiological fingerprints to assess the efficacy of esterification process. The presence of $3400 \mathrm{~cm}^{-1}$ (region I) was noted with broad intensity at $5 \mathrm{mg} / \mathrm{mL}(0.04)$ rather than $1 \mathrm{mg} / \mathrm{mL}$ (0.03), and the wavenumber of $3400 \mathrm{~cm}^{-1}$ was attributed to $\mathrm{O}-\mathrm{H}$ stretching of aromatic and aliphatic hydroxyl groups [59-61]. The peak of $3400 \mathrm{~cm}^{-1}$ at $1 \mathrm{mg} /$ $\mathrm{mL}$ becomes more flattened. As hypothesised, the findings showed that more material or lignin concentration in the soluble lignin extract, the more source of $\mathrm{O}-\mathrm{H}$ bonds in the esterified lignin.

When comparison was made to modified lignin prepared to $1 \mathrm{mg} / \mathrm{mL}$, the region II and III in Fig. 9 of modified lignin from $5 \mathrm{mg} / \mathrm{mL}$ showed no difference in intensity of the peaks around 2938, 2850, 1760 and $1740 \mathrm{~cm}^{-1}$. Strong absorptions at 2938 and $2850 \mathrm{~cm}^{-1}$ of modified lignin (region II) at both lignin concentrations arise from long chain alkyl groups (aliphatic carbon) which are present in fatty acid chloride, dodecanoyl chloride [35], and the $\mathrm{CH}$ stretching vibrations in methyl and methylene groups [62]. A clear evidence of a sharp intensity peak at 1760 and $1740 \mathrm{~cm}^{-1}$ (region III) at both lignin concentrations that related to aromatic and aliphatic ester bonds were observed [63]. This indicates that the esterification process was successful.

Given that the findings of modified lignin showed the esterification was successfully conducted at both lignin concentrations, the results from such FTIR analysis should thus consequently be compared with the filtrate, dodecanoyl chloride and blank solution of FTIR spectra to support the evidence of esterification efficacy. Dodecanoyl chloride is the $\mathrm{C}_{12}$ fatty acid chloride that reacted with lignin to form ester. Upon filtration after esterification process, esterified lignin was separated from the filtrate. The filtrate may consist of ethanol, water and $2 \%$ of ice-cold hydrochloric acid. The chemical modification via esterification was confirmed by FTIR and the spectra of the filtrate, dodecanoyl chloride and blank solution of each lignin concentration are shown in Fig. 10.

The spectra between modified lignin at both concentrations were compared with the spectra of dodecanoyl chloride. The disappearance peak of dodecanoyl chloride, $1800 \mathrm{~cm}^{-1}$ associated to $\mathrm{COCl}$ and $1700 \mathrm{~cm}^{-1}$ referred to dodecanoyl acid in Fig. 10 (labelled as I), strongly support that the modified lignin does not contain any traces of unreacted fatty acid [35]. Figure 10 shows that the spectra of filtrate had a similar chemical characterisation with the spectra of blank solution. Both spectra, filtrate and blank solution were dominated by water at 5 and $1 \mathrm{mg} /$ 


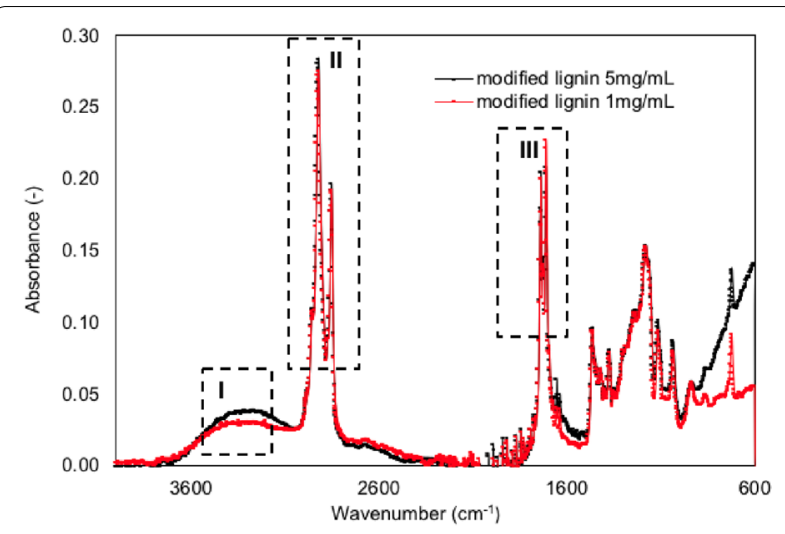

Fig. 9 FTIR spectra of modified lignin at different ethanol concentration

$\mathrm{mL}$ lignin concentrations, in turn the spectra produced were overlap with other modes of interest.

In general, the findings of this study implied that esterification works well with both lignin concentrations, 5 and $1 \mathrm{mg} / \mathrm{mL}$ of soluble lignin extract. However, the utilisation of $1 \mathrm{mg} / \mathrm{mL}$ lignin concentration of soluble lignin extract is not feasible for lignin modification process. Taking into account of high dilution may lead to excessive energy costs in process if using $1 \mathrm{mg} / \mathrm{mL}$ lignin concentration of soluble lignin extract, it is recommended the soluble lignin extract produced from sequential extraction processing routes that had $5 \mathrm{mg} / \mathrm{mL}$ lignin concentration is used directly for lignin modification process.

\section{Conclusion}

In summary, given that the fact of this study was only a preliminary attempt to assess the effect of ethanol concentration on lignin aggregation behaviour, it is hardly surprising that the results showed a complex structural lignin macromolecules dispersion or assembly. Low average particle size could be effectively produced at lowest ethanol concentration of soluble lignin extract. Nevertheless, these findings need to be interpreted with caution due to the dispersion cannot lead to particle size or molecular weight reduction. In a study lignin aggregation behaviour at different ethanol concentration, the reduction of particle size and the availability of hydroxyl group has thrown up many questions in need of further investigation. Further research should be concentrated on the validation of particle size and determination of hydroxyl groups via different established methods. Understanding selective lignin behaviour offers valuable insight into bioreplacement ratio functionalities and allows the chemical transformation of lignin streams in bio-based industrial applications.

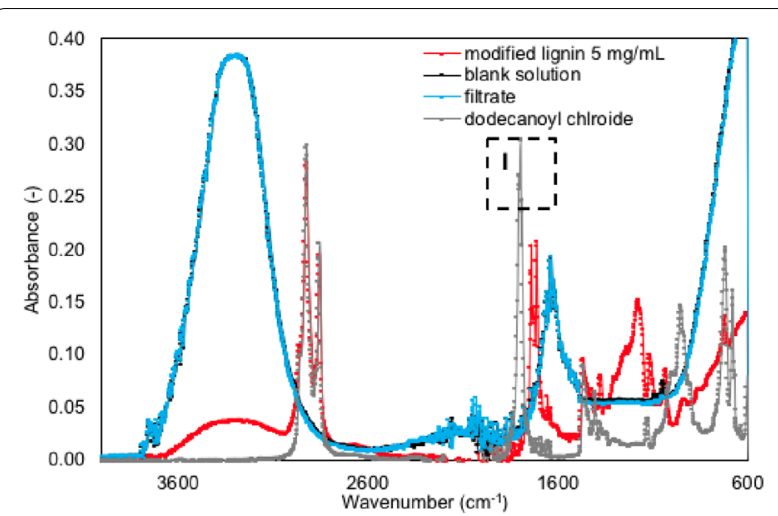

(a)

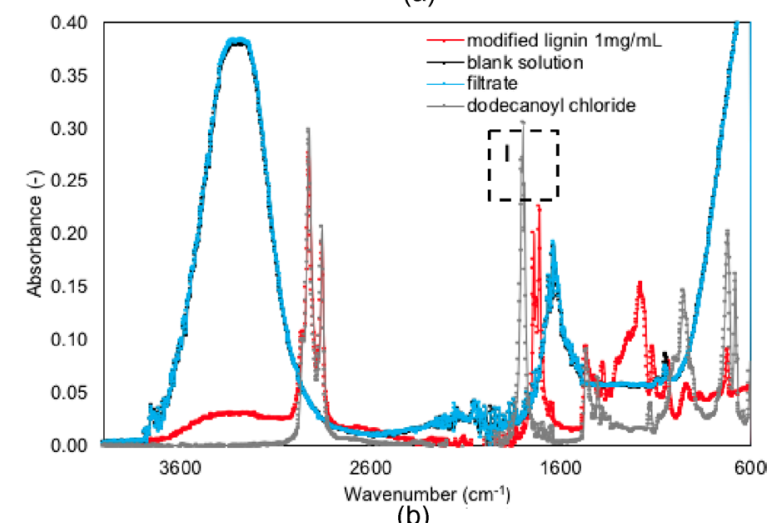

Fig. 10 FTIR spectra of modified lignin, blank solution, filtrate and dodecanoyl chloride at $\mathbf{a} 5$ and $\mathbf{b} 1 \mathrm{mg} / \mathrm{mL}$ lignin concentration

The present study makes noteworthy contributions that an efficient process for completely separating main biomass components in a biorefinery approach produces soluble lignin extract that provides high availability of hydroxyl groups in addition to hemicellulose and cellulose recovery. The available reactive hydroxyl groups in lignin offer exciting possibilities for lignin chemical modification. Moreover, a less time consuming and less costly method to use directly the soluble lignin extract instead to dissolve lignin powder in the solvent, is recommended for lignin chemical modification. The modified lignin under esterification derived using the soluble lignin extract directly from sequential extraction $(5 \mathrm{mg} /$ $\mathrm{mL}$ ) could be used further with increased functionalities in the bio-replacement ratios and facilitated the chemical transformation of lignin stream in bio-based industrial applications.

\section{Acknowledgements}

We would like to sincerely thank the Ministry of Higher Education Malaysia and Universiti Putra Malaysia for providing scholarship during PhD. 


\section{Authors' contributions}

$\mathrm{MHH}$ : data curation, formal analysis, investigation, methodology, writingoriginal draft. SB: conceptualisation, data curation, supervision, project administration, validation. PC: supervision, writing - review and editing, conceptualisation, methodology. All authors read and approved the final manuscript.

\section{Funding}

The authors would also like to thank Phytatec (U.K.) Ltd. for providing biomass feedstock. This research was funded by Ministry of Higher Education Malaysia and Universiti Putra Malaysia under Skim Latihan IPTA and the APC was funded by Universiti Putra Malaysia.

\section{Availability of data and materials}

Not applicable.

\section{Declarations}

\section{Ethics approval and consent to participate}

Not applicable.

\section{Consent for publication}

The authors have given their personal consent for publication.

\section{Competing interests}

The authors declare that they have no competing interests.

\section{Author details}

${ }^{1}$ Department of Biological and Agricultural Engineering, Faculty of Engineering, Universiti Putra Malaysia, 43400 Serdang, Selangor, Malaysia. ${ }^{2}$ SMART Farming Technology Research Centre, Faculty of Engineering, Universiti Putra Malaysia, 43400 Serdang, Selangor, Malaysia. ${ }^{3}$ School of Chemical Engineering, University of Birmingham, Edgbaston B15 2TT, UK. ${ }^{4}$ Phytatec (UK) Ltd., Plas Gogerddan SY23 3EB, Aberystwyth, UK. ${ }^{5}$ School of Engineering, University of Greenwich, Medway Campus, Central Avenue, Chatham Maritime ME4 4TB, Kent, UK.

\section{Received: 26 August 2021 Accepted: 9 October 2021}

Published online: 28 December 2021

\section{References}

1. IEA Bioenergy. Biorefineries: adding value to the sustainable utilisation of biomass. New Zealand: IEA Bioenergy Secretariat; 2009.

2. Glasser WG. About Making Lignin Great Again-Some Lessons From the Past. Front Chem. 2019;7:1-17.

3. Damaso MCT, Machado CMM, Rodrigues DS, Belem SG, Salum TFC. Bioprocesses for biofuels: an overview of the Brazilian case. Chem Biol Technol Agric. 2014;1(1):1-8.

4. Yuan T-Q, Xu F, Sun R-C. Role of lignin in a biorefinery: separation characterisation and valorisation. J Chem Technol Biotechnol. 2013;88(3):34652. https://doi.org/10.1002/jctb.3996.

5. Yuan Z, Cheng S, Leitch M, Xu CC. Hydrolytic degradation of alkaline lignin in hot-compressed water and ethanol. Bioresour Technol. 2010;101(23):9308-13.

6. Hamzah MH, Bowra S, Cox P. Effects of ethanol concentration on organosolv lignin precipitation and aggregation from Miscanthus $x$ giganteus. Processes. 2020;8(7):1-16.

7. Duval A, Lawoko M. A review on lignin-based polymeric, micro- and nano-structured materials. React Funct Polym. 2014;85:78-96.

8. Zadeh EM, Keefe SFO, Kim Y. Utilization of lignin in biopolymeric packaging films. ACS Omega. 2018;3(7):7388-98.

9. Luo X, Mohanty A, Misra M. Lignin as a reactive reinforcing filler for waterblown rigid biofoam composites from soy oil-based polyurethane. Ind Crops Prod. 2013;47:13-9.

10. Solt P, Konnerth J, Gindl-Altmutter W, Kantner W, Moser J, Mitter R, et al. Technological performance of formaldehyde-free adhesive alternatives for particleboard industry. Int J Adhes Adhes. 2019;94:99-131. https://doi. org/10.1016/j.ijadhadh.2019.04.007.

11. Mahmood N, Yuan Z, Schmidt J, Xu C. Depolymerisation of lignins and their applications for the preparation of polyols and rigid polyurethane foams: A review. Renew Sustain Energy Rev. 2016;60:317-29.

12. Laurichesse $S$, Avérous L. Chemical modification of lignins: Towards biobased polymers. Prog Polym Sci. 2014;39(7):1266-90.

13. Londoño Zuluaga C, Du J, Chang H-M, Jameel H, Gonzalez RW. Lignin modifications and perspectives towards applications of phenolic foams: a review. BioResources. 2018;13(4):9158-79.

14. Achyuthan KE, Achyuthan AM, Adams PD, Dirk SM, Harper JC, Simmons BA, et al. Supramolecular self-assembled chaos: Polyphenolic lignin's barrier to cost-effective lignocellulosic biofuels. Molecules. 2010;15(12):8641-88.

15. Radotić K, Micić M, Milorad J. Scanning Probe Microscopy of Plant Cell Wall and its Constituents. In: Jena BP, Horber HJK, editors. Force Microscopy: Applications in Biology and Medicine. United States of America: Wiley; 2006. p. 303.

16. Norgren $M$, Edlund $H$, Wågberg $L$. Aggregation of lignin derivatives under alkaline conditions. Kinetics Aggr Struct Langmuir. 2002;18(7):2859-65.

17. Hamzah MH. Extraction and Modification of Lignin to Support Enhanced Utilisation using Critical Fluid. PhD thesis. University of Birmingham; 2018.

18. Zhao W, Simmons B, Singh S, Ragauskas A, Cheng G. From lignin association to nano-/micro-particle preparation: extracting higher value of lignin. Green Chem. 2016;18(21):5693-700.

19. Cachet N, Camy S, Benjelloun-Mlayah B, Condoret J-S, Delmas M. Esterification of organosolv lignin under supercritical conditions. Ind Crops Prod 2014;58:287-97.

20. Lisperguer J, Perez P, Urizar S. Structure and thermal properties of lignins: Characterisation by infrared spectroscopy and differential scanning calorimetry. J Chil Chem Soc. 2009;54(4):460-3.

21. Hamzah MH, Bowra S, Simmons MJH, Cox PW. The Impact of Process Parameters on the Purity and Chemical Properties of Lignin Extracted from Miscanthus x giganteus using a Modified Organosolv Method. In: 24th European Biomass Conference and Exhibition. Amsterdam: ETAFlorence Renewable Energies; 2016. p. 1754-9.

22. Roque RMN, Baig MN, Leeke GA, Bowra S, Santos RCD. Study on sub-critical water mediated hydrolysis of Miscanthus a lignocellulosic biomass. Resour Conserv Recycl. 2012;59:43-6.

23. Hamzah MH, Bowra S, Cox P. Purity and structural composition of lignin isolated from Miscanthus x giganteus by sub-critical water extraction with associated modifiers. J Agric Food Eng. 2020;1(1):1-12.

24. Šurina I, Jablonskỳ M, Ház A, Sladková A, Briškárová A, Kačík F, et al. Characterisation of non-wood lignin precipitated with sulphuric acid of various concentrations. BioResources. 2015;10(1):1408-23.

25. Aleš H, Michal J, Lenka D, Alexandra S, Igor Š. Thermal properties and size distribution of lignins precipitated with sulphuric acid. Wood Res. 2015;60(3):375-84.

26. Donaldson LA. Critical assessment of interference microscopy as a technique for measuring lignin distribution in cell walls. New Zeal J For Sci. 1985;15(3):349-60.

27. Stewart HE. Development of food-grade microparticles from lignin. PhD thesis. Massey University, New Zealand; 2015.

28. Olson E. Particle shape factors and their use in image analysis-part 1: Theory. J GXP Compliance. 2011;15(3):85-96.

29. Willen U. Automation in image analysis for particle size and shape measurement. GIT Lab J. 2008;7(8):34-6.

30. Liu EJ, Cashman KV, Rust AC. Optimising shape analysis to quantify volcanic ash morphology. Geo Res J. 2015;8:14-30.

31. Jablonsky M, Kocis J, Haz A. Characterisation and comparison by UV spectroscopy of precipitated lignins and commercial lignosulfonates. Cellul Chem Technol. 2015;34(49):267-74

32. Zakis GF. Hydroxyl Groups. In: Joyce T, Brezny R, editors. Functional Analysis of Lignins and Their Derivatives. Atlanta: TAPPI Press; 1994. p. 43-9.

33. Vallejos ME, Felissia FE, Curvelo AAS, Zambon MD, Ramos L, Area MC. Chemical and physico-chemical characterisation of lignins obtained from ethanol-water fractionation of bagasse. BioResources. 2011;6(2):1158-71. 
34. Sluiter A, Hames B, Hyman D, Payne C, Ruiz R, Scarlata C, et al. Determination of Total Solids in Biomass and Total Dissolved Solids in Liquid Process Samples. National Renewable Energy Laboratory (NREL). Colorado; 2008.

35. Gordobil O, Egüés I, Labidi J. Modification of Eucalyptus and Spruce organosolv lignins with fatty acids to use as filler in PLA. React Funct Polym. 2016;104:45-52.

36. Jackson GA, Burd AB. Critical Review Aggregation in the Marine Environment. Environ Sci Technol. 1998;32(19):2805-14.

37. Claverie J, Marie-Thérèse C, Pichot C. Polymers in Dispersed Media I: International Conference on Polymers in Dispersed Media (Macromolecular Symposia). Miesel I, Spiegel S, editors. France: Wiley-VCH Verlag GmbH \& Co. KGaA; 2010. p. 273-4.

38. Dan X, Kuanjun F, Shaohai F. Effects of ethanol on the stability of pigment colloidal dispersion. J Dispers Sci Technol. 2009;30(4):510-3.

39. Bergeret G, Gallezot P. Particle Size and Dispersion Measurements. In: Handbook of Heterogeneous Catalysis. WILEY-VCH Verlag GmbH \&Co. KGaA; 2008. p. 738-65.

40. Xiong F, Han Y, Wang S, Li G, Qin T, Chen Y, et al. Preparation and formation mechanism of size-controlled lignin nanospheres by self-assembly. Ind Crops Prod. 2017;100:146-52.

41. Li H, Deng Y, Liu B, Ren Y, Liang J, Qian Y, et al. Preparation of Nanocapsules via the Self-Assembly of Kraft Lignin: A Totally Green Process with Renewable Resources. ACS Sustain Chem Eng. 2016;4(4):1946-53.

42. Qian Y, Deng Y, Qiu X, Li H, Yang D. Formation of uniform colloidal spheres from lignin, a renewable resource recovered from pulping spent liquor. Green Chem. 2014;16(4):2156.

43. Rao X, Liu Y, Zhang Q, Chen W, Liu Y, Yu H. Assembly of Organosolv Lignin Residues into Submicron Spheres: The Effects of Granulating in Ethanol/ Water Mixtures and Homogenisation. ACS Omega. 2017;2(6):2858-65. https://doi.org/10.1021/acsomega.7b00285.

44. Da Silva DC, Ricken I, Silva MADR, Machado VG. Solute-solvent and solvent-solvent interactions in the preferential solvation of Brooker's merocyanine in binary solvent mixtures. J Phys Org Chem. 2002;15(7):420-7.

45. Maitra A, Bagchi S. Study of solute-solvent and solvent-solvent interactions in pure and mixed binary solvents. J Mol Liq. 2008;137(1):131-7.

46. Snowden MJ, Gracra LH, Nur H. Heteroflocculation Studies of Colloidal Poly(N-isopropylacrylamide) Microgels with Polystryrene Latex Particles: Effect of Particle Size, Temperature and Surface Charge. In: Biggs S, Cosgrove T, Dowding P, editors. New Frontiers in Colloid Science: A Celebration of the Career of Brian Vincent. Berlin: RSC Publishing; 2008. p. 149-64.

47. Amin S, Barnett GV, Pathak JA, Roberts CJ, Sarangapani PS. Protein aggregation, particle formation, characterisation and rheology. Curr Opin Colloid Interface Sci. 2014;19(5):438-49.

48. Lomakin A, Teplow DB, Benedek GB. Quasielastic light scattering for protein assembly studies. Methods Mol Biol. 2005;299:153-74.

49. Bevilaqua T, Gonçalves TF, Venturini CG, Machado VG. Solute-solvent and solvent-solvent interactions in the preferential solvation of 4-[4-(dimethylamino)styryl]-1-methylpyridinium iodide in 24 binary solvent mixtures. Spectrochim Acta Part A Mol Biomol Spectrosc. 2006;65(3):535-42.
50. Jones OG, McClements DJ. Functional biopolymer particles: Design, fabrication, and applications. Compr Rev Food Sci Food Saf. 2010;9(4):374-97.

51. McClements DJ. Nanoparticle- and Microparticle-based Delivery Systems: Encapsulation, Protection and Release of Active Compounds. Boca Raton, Fl: CRC Press; 2015. p. 572.

52. Fu Q-S, Xue Y-Q, Cui Z-X, Wang M-F. Study on the size-dependent oxidation reaction kinetics of nanosized zinc sulfide. J Nanomater. 2014;2014:1-8

53. Jääskeläinen AS, Liitiä T, Mikkelson A, Tamminen T. Aqueous organic solvent fractionation as means to improve lignin homogeneity and purity. Ind Crops Prod. 2017;103:51-8. https://doi.org/10.1016/j.indcrop.2017.03. 039.

54. Kim KH, Kim CS. Recent efforts to prevent undesirable reactions from fractionation to depolymerization of lignin: Toward maximizing the value from lignin. Front Energy Res. 2018;6:1-7.

55. Domínguez-Robles J, Tamminen T, Liitiä T, Peresin MS, Rodríguez A, Jääskeläinen AS. Aqueous acetone fractionation of kraft, organosolv and soda lignins. Int J Biol Macromol. 2018;106:979-87. https://doi.org/10. 1016/j.jijbiomac.2017.08.102

56. Sadeghifar H, Wells T, Le RK, Sadeghifar F, Yuan JS, Jonas RA. Fractionation of organosolv lignin using acetone: water and properties of the obtained fractions. ACS Sustain Chem Eng. 2017:5(1):580-7.

57. El Mansouri NE, Yuan Q, Huang F. Characterisation of alkaline lignins for use in phenol-formaldehyde and epoxy resins. BioResources. 2011;6:2647-62.

58. Bridson JH, Van De Pas DJ, Fernyhough A. Succinylation of three different lignins by reactive extrusion. J Appl Polym Sci. 2013;128(6):4355-60.

59. Alriols MG, García A, Llano-ponte R, Labidi J. Combined organosolv and ultrafiltration lignocellulosic biorefinery process. Chem Eng J. 2010;157(1):113-20

60. Boeriu CG, Bravo D, Gosselink RJA, van Dam JEG. Characterisation of structure-dependent functional properties of lignin with infrared spectroscopy. Ind Crops Prod. 2004;20(2):205-18.

61. Pandey KK. A study of chemical structure of soft and hardwood and wood polymers by FTIR spectroscopy. J Appl Polym Sci. 1999;71(12):1969-75.

62. Szczepkowski A, Nicewicz D, Koczon P. The relationship between tree health and chemical composition of beech (Fagus sylvatica L) and oak (Quercus robur L) wood of polish provenances. Acta Sci Pol Silvarum Colendarum Ratio Ind Lignaria. 2007:6(3):77-88.

63. Pawar SN, Venditti RA, Jameel H, Chang H-M, Ayoub A. Engineering physical and chemical properties of softwood kraft lignin by fatty acid substitution. Ind Crops Prod. 2016;89:128-34.

\section{Publisher's Note}

Springer Nature remains neutral with regard to jurisdictional claims in published maps and institutional affiliations.

\section{Submit your manuscript to a SpringerOpen ${ }^{\circ}$ journal and benefit from:}

- Convenient online submission

- Rigorous peer review

- Open access: articles freely available online

- High visibility within the field

Retaining the copyright to your article

Submit your next manuscript at springeropen.com 